\title{
Left Gluteus Medius
}

National Cancer Institute

\section{Source}

National Cancer Institute. Left Gluteus Medius. NCI Thesaurus. Code C105638.

One of the three gluteal muscles on the lateral surface of the pelvic bone that abducts and rotates the thigh located on the left side of the body. 